\title{
Efeitos da Adubação e de Nematicida no Crescimento e na Produção da Palma Forrageira (Opuntia ficus indica Mill) cv. Gigante ${ }^{1}$
}

\section{Margareth Maria Teles ${ }^{2}$, Mércia Virgínia Ferreira dos Santos ${ }^{3}$, José Carlos Batista Dubeux Júnior ${ }^{4}$, Egídio Bezerra Neto ${ }^{3}$, Rinaldo Luiz Caraciolo Ferreira ${ }^{3}$, Jorge Eduardo Cavalcanti Lucena $^{5}$, Mário de Andrade Lira ${ }^{6}$}

\begin{abstract}
RESUMO - O experimento foi realizado em telado do Departamento de Zootecnia da UFRPE, objetivando medir o efeito da adubação e de nematicida no crescimento e produção da palma, com sintoma de amarelecimento. Os tratamentos experimentais constaram da adição ou não de macronutrientes, micronutrientes e de nematicida em um delineamento experimental em blocos casualizados. Para número de cladódios primários, a análise de variância demonstrou efeito não significativo pelo teste F. Para número total de cladódios, número de cladódios secundários, área de cladódio, índice de área de cladódios e produção de matéria seca, a análise de variância revelou efeito significativo. Não houve efeito dos micronutrientes e de nematicida no grupo dos tratamentos de Solução de Macronutrientes Completa para número de cladódios primários, número de cladódios secundários, área de cladódio, índice de área de cladódios e produção de matéria seca, sendo a média geral 1,$56 ; 0,84 ; 811,11 \mathrm{~cm}^{2} ; 1,15$ e $42,73 \mathrm{~g} /$ vaso, respectivamente.
\end{abstract}

Palavras-chave: área de cladódio, índice de área de cladódio, macronutrientes, micronutrientes

\section{Effects of Nematicide and Fertilization on the Forage Cactus (Opuntia ficus indica Mill) cv. "Gigante" Growth and Production}

\begin{abstract}
The experiment was performed in a green house at the Animal Science Department of the Pernambuco Federal Rural University (UFRPE) and aimed to study the nematicide and fertilization effects on the forage cactus cv. "Gigante" growth and production using propagative materials with clorotic symptom. The experimental treatments tested the addition or no of macronutrients, micronutrients and nematicide. It was used a complete randomized block design. Considering the primary cladode's number, no differences were found by F test. Significative differences were found to the total number of cladodes, secondary cladode number, cladode area, cladode area index and dry matter yield. The addition of micronutrients and nematicide did not influence the primary and secondary cladode number, cladode area, cladode area index and dry matter yield, and the mean values obtained were $1.56,0.84,811.11 \mathrm{~cm}^{2}, 1.15$ and $42.73 \mathrm{~g} /$ pot, respectively.
\end{abstract}

Key Words: cladode area, cladode area index, macronutrients, micronutrients

\section{Introdução}

A baixa disponibilidade de forragem nas regiões semi-áridas tem sido um problema constante para a pecuária do Nordeste brasileiro, devido principalmente a longos períodos de estiagem. A palma forrageira apresenta-se como uma alternativa primordial para estas regiões, visto que é uma cultura que apresenta aspecto fisiológico especial quanto à absorção, aproveitamento e perda de água, sendo bem adaptada às condições adversas do semi-árido, suportando prolongados períodos de estiagem.

O nível de adubação é fator determinante na pro- dução de matéria verde, principalmente, quando se trata de plantio adensado de palma. Considerando que os teores de elementos minerais encontrados na matéria seca da palma forrageira obtidos por Santos (1989) foram de 0,$90 ; 0,16$; e 2,58\% para nitrogênio, fósforo e potássio, respectivamente, e supondo-se uma produção de $10 \mathrm{t}$ de $\mathrm{MS} / \mathrm{ha}$, estima-se que as quantidades desses nutrientes exportados do solo seriam de $90 \mathrm{~kg}$ de N/ha, $16 \mathrm{~kg}$ de $\mathrm{P} / \mathrm{ha}$ e $258 \mathrm{~kg}$ de $\mathrm{K} / \mathrm{ha}$.

$\mathrm{O}$ espaçamento de plantio da palma forrageira varia de acordo com a fertilidade do solo, quantidade de chuvas, finalidade de exploração e com o consórcio a ser utilizado. O cultivo da palma forrageira em

\footnotetext{
${ }_{1}^{1}$ Parte da Dissertação de Mestrado em Zootecnia apresentada pelo primeiro autor à Universidade Federal Rural de Pernambuco (UFRPE).

2 Professora da UFPI.

${ }^{3}$ Professor da UFRPE. R. Dom Manoel de Medeiros, s/n, Dois Irmãos, Recife-PE, 52171.900. E.mail: rmsantos@elogica.com.br

${ }^{4}$ Professor da UFRPE, Bolsista do CNPq. E.mail:dubeux.ufl.edu

${ }^{5}$ Aluno do Programa de Pós-Graduação em Zootecnia-UFRPE.

${ }^{6}$ Pesquisador do IPA, Bolsista do CNPq. E.mail: mlira@hotlink.com.br
} 
espaçamento adensado tem sido mais utilizado recentemente. Nesses espaçamentos, os tratos culturais e a colheita são dificultados, aumentando os gastos com a mão de obra. Além desses aspectos, neste caso, ocorre uma maior quantidade de nutrientes extraídos do solo, considerando que em espaçamento 2,0 $\mathrm{m} \times 1,0 \mathrm{~m}$ tem-se 5.000 plantas/ha, enquanto que no espaçamento $1,0 \mathrm{~m} \times 0,25 \mathrm{~m}$ a quantidade de plantas é oito vezes maior, ou seja, $40.000 \mathrm{plantas} / \mathrm{ha}$, sendo necessário um maior cuidado com as adubações. Por outro lado, com espaçamento adensado, tem-se observado sintoma de amarelecimento do palmal nos Estados de Pernambuco e Alagoas. Supõe-se que tal amarelecimento, com base em observação in loco, seja devido à deficiência de algum nutriente no solo ou ao aparecimento de nematóides que pode estar inibindo a absorção de nutriente pela cultura.

Assim, o objetivo deste trabalho foi estudar o efeito da adubação e de nematicida no crescimento e produção da palma forrageira cv. Gigante cultivada em solo de área de ocorrência de amarelecimento das plantas.

\section{Material e Métodos}

O experimento foi conduzido em telado do Departamento de Zootecnia da Universidade Federal Rural de Pernambuco, no período de junho de 1998 a março de 1999. Utilizou-se amostra de solo proveniente da Estação Experimental de Caruaru - IPA, onde foi observado o amarelecimento da palma forrageira. A análise de fertilidade do solo foi realizada segundo metodologia da EMBRAPA (1997). A análise de solo revelou os seguintes resultados: $\mathrm{Na}^{+}=0,09$ cmolc. $\mathrm{kg}^{-1}$; $\mathrm{K}^{+}=0,32$ cmolc. $\mathrm{kg}^{-1} ; \mathrm{Ca}^{2+}=1,90$ cmolc. $\mathrm{kg}^{-1}$; $\mathrm{Mg}^{2+}=0,90$ cmolc. $\mathrm{kg}^{-1} ; \mathrm{H}^{+}=1,99$ cmolc. $\mathrm{kg}^{-1}$; $\mathrm{Al}^{3+}=0,05$ cmolc.kg ${ }^{-1} ; \mathrm{pH}=5,5 ; \mathrm{P}=8,63 \mathrm{mg} \cdot \mathrm{kg}^{-1}$; $\mathrm{N}=0,6$ g. $\mathrm{kg}^{-1} ;$ M.O. $=7,6 \mathrm{~g} \cdot \mathrm{kg}^{-1}$.

Utilizaram-se vasos de plástico medindo $30 \mathrm{~cm}$ de diâmetro por $22 \mathrm{~cm}$ de altura. Nos vasos foram colocados drenos de aproximadamente $10 \mathrm{~cm}$ de comprimento e diâmetro de $1 / 4$ ", além de uma camada de brita para evitar o entupimento dos drenos. A brita utilizada foi lavada em água corrente e depois fervida. Foram colocados quinze quilos de solo em cada vaso.

Para o plantio utilizaram-se cladódios de palma (Opuntia ficus indica, Mill. cv. Gigante) provenientes também da Estação Experimental de Caruaru IPA, do local onde foi observado o amarelecimento das plantas. Os cladódios foram deixados à sombra durante cinco dias e o plantio foi efetuado em 26 de junho de 1998, colocando-se um cladódio por vaso, verticalmente, com a parte cortada voltada para o solo a uma profundidade de aproximadamente $20 \mathrm{~cm}$ ou o suficiente para que metade do cladódio ficasse enterrado. Antes do plantio, foram pesados todos os cladódios e os pesos foram considerados para a formação dos blocos. Foi utilizada água destilada, aplicada duas vezes por semana até a drenagem, sendo a solução drenada, recolhida em um recipiente e retornada ao vaso.

Os tratamentos experimentais foram avaliados num delineamento em blocos ao acaso com 4 repetições e constaram da adição ou não de macronutrientes, micronutrientes e de um nematicida sistêmico, no cultivo da palma forrageira em vasos, perfazendo 17 tratamentos, conforme descritos a seguir: testemunha, testemunha mais nematicida, testemunha mais nitrogênio, testemunha mais fósforo, testemunha mais potássio, testemunha mais cálcio, testemunha mais magnésio, testemunha mais enxofre, solução de macronutrientes completa $\mathrm{SMC}(\mathrm{N}, \mathrm{P}$, $\mathrm{K}, \mathrm{Ca}, \mathrm{Mg}, \mathrm{S}), \mathrm{SMC}$ menos nitrogênio, SMC menos fósforo, SMC menos potássio, SMC menos cálcio, SMC menos magnésio, SMC menos enxofre, SMC mais micronutrientes, $\mathrm{SMC}$ mais micronutrientes mais nematicida.

A aplicação dos tratamentos experimentais foi realizada 52 dias após o plantio, quando $80 \%$ dos vasos apresentavam o aparecimento de pelo menos um cladódio. Foram utilizados os níveis equivalentes de adubação: $\mathrm{N}$ - $200 \mathrm{~kg} / \mathrm{ha} ; \mathrm{P}_{2} \mathrm{O}_{5}-100 \mathrm{~kg} / \mathrm{ha} ; \mathrm{K}_{2} \mathrm{O}$ $200 \mathrm{~kg} / \mathrm{ha} ; \mathrm{Ca}-250 \mathrm{~kg} / \mathrm{ha} ; \mathrm{Mg}-80 \mathrm{~kg} / \mathrm{ha}$ e S - $20 \mathrm{~kg} / \mathrm{ha}$. Os níveis de adubação utilizados basearam-se nos teores médios de nutrientes minerais encontrados em plantas de palma e nos resultados médios da análise do solo de Caruaru - PE, sendo aplicados os adubos na parte superficial do solo. As fontes de nutrientes utilizadas, conforme os tratamentos experimentais, foram: uréia, superfosfato triplo, cloreto de potássio, óxido de cálcio, cloreto de magnésio, sulfato de magnésio, fosfato de sódio, sulfato de amônio, sulfato de sódio e para os micronutrientes foi utilizado o coquetel de micronutrientes e Fe - EDTA da solução de Hoagland \& Arnon (1950).

A adubação nitrogenada foi parcelada em duas vezes, sendo a primeira adubação aplicada juntamente com os outros tratamentos, ou seja, a partir do aparecimento de pelo menos um cladódio. A segunda parcela foi aplicada 45 dias após a primeira adubação. 
Os cálculos para quantidade de cada nutriente para os vasos foram feitos de acordo com a quantidade de solo colocada em cada vaso $(15 \mathrm{~kg})$, densidade aparente do solo $\left(1,4 \mathrm{t} / \mathrm{m}^{3}\right)$ e profundidade efetiva das raízes $(20 \mathrm{~cm})$.

Conforme os tratamentos experimentais, foram aplicados $5 \mathrm{~g}$ /vaso do nematicida sistêmico Carbofuran (Furadan, $50 \mathrm{~g}$ ) na parte superficial do solo do vaso.

Foi realizada a contagem, a cada 28 dias, de número de cladódios por planta e por ordem de aparecimento, e mensurado o comprimento, largura e perímetro da parte aérea, utilizando-se fita métrica e para medidas de espessura do cladódio um paquímetro.

A colheita foi realizada após nove meses de cultivo, devido algumas plantas apresentarem tombamento, o que está associado, provavelmente, ao fato do material de plantio apresentar sintomas amarelecimento e presença de fungos.

Os dados obtidos para número de cladódios/ planta e número de cladódios por ordem/planta, foram transformados para $\sqrt{x}$ e $\sqrt{x+1}$, respectivamente, para se proceder à análise de variância.

A parte aérea foi colhida por planta e por ordem de aparecimento dos cladódios, pesada, fragmentada e acondicionada em sacos de papel devidamente identificados, sendo, em seguida, colocada em estufa de aeração forçada a $55^{\circ} \mathrm{C}$ até peso constante. Após a pré-secagem, foi realizada a moagem em moinho de facas com peneiras de $1 \mathrm{~mm} \mathrm{e}$, em seguida, colocadas em sacos de plásticos já identificados para as análises subseqüentes.

Foram avaliados: área de cladódio (Santos, 1992), índice de área de cladódio, percentagem de matéria seca (Silva, 1990), produção de matéria seca, alocação de biomassa verde ou seca da parte aérea e raiz, identificação e qualificação de nematóides no solo e na raiz, segundo o método de Jenkins (1964).

A análise dos dados obtidos foi realizada por meio do programa computacional SAEG (Sistema para Análises Estatísticas e Genéticas), desenvolvido pela Universidade Federal de Viçosa.

As médias dos tratamentos foram submetidas ao teste de Scott-Knott (Scott \& Knott, 1974), a 5\% de probabilidade.

Para produção de matéria verde, produção de matéria seca, teor de matéria seca do cladódio-planta e raiz e alocação de biomassa, foram utilizadas apenas três repetições, em virtude de um bloco ter sido reservado para avaliação de nematóides na raiz e no solo.

\section{Resultados e Discussão}

Os resultados do número total de cladódio/planta e número de cladódio por ordem/planta, estão apresentados na Tabela 1. Para número de cladódios primários/planta, não foi verificado efeito dos tratamentos $(\mathrm{P}>0,05)$ pelo teste $\mathrm{F}$. Para número total de cladódios/planta, número de cladódios secundários/ planta, a análise de variância evidenciou diferença significativa $(\mathrm{P}<0,05)$ entre tratamentos.

Os tratamentos testemunha $+\mathrm{N}$, SMC, SMC com subtração de $\mathrm{N}, \mathrm{K}, \mathrm{Ca}, \mathrm{Mg}$ e $\mathrm{S}, \mathrm{SMC}+$ micronutrientes e $\mathrm{SMC}+$ micronutrientes + nematicida apresentaram maior número total de cladódios/planta $(\mathrm{P}<0,05)$, quando comparados aos demais tratamentos, sendo a média mínima e máxima para número total de cladódios/planta de 1,00 e 4,00 , respectivamente. Estes valores são inferiores aos encontrados por Santos (1992), que foram de 7,3 cladódios/planta para palma aos 9 meses de idade, e Silva et al. (1998), que encontraram 6,0 $\pm 1,06$ aos 8 meses de idade, o que pode estar associado ao fato de o presente trabalho ter sido desenvolvido em telado, bem como o material de plantio apresentar sintomas de amarelecimento, o que pode ter comprometido o crescimento das plantas. Considerando o grupo SMC, observa-se que, quando o fósforo foi retirado da solução de macronutrientes completa, houve redução do número total de cladódio/planta, ratificando a afirmação de Lobato et al. (1994), de que a deficiência de fósforo é um fator limitante a capacidade produtiva das forrageiras. Por outro lado, considerando o grupo das testemunhas, observa-se que o acréscimo de nitrogênio, promoveu aumento do número total de cladódio/planta. Provavelmente, tal resultado esteja associado ao baixo teor de matéria orgânica do solo, 7,60 g. $\mathrm{kg}^{-1}$.

Os tratamentos SMC, SMC com subtração de $\mathrm{Ca}, \mathrm{Mg}$ e $\mathrm{S}, \mathrm{SMC}$ mais micronutrientes e $\mathrm{SMC}+$ micronutrientes + nematicida apresentaram maior número de cladódios secundários/planta, quando comparados aos demais tratamentos, variando de 0,25 a 2,0 cladódios secundários/planta.

Não se observou efeito significativo $(\mathrm{P}>0,05)$ quando se adicionaram os micronutrientes e nematicida à solução de macronutrientes completa, para número total de cladódios por planta e número de cladódios de ordem secundária. Considerando o grupo dos tratamentos SMC, observa-se que a subtração de N, P e K reduziu o número de brotação secundária 
Tabela 1 - Número total de cladódio/planta e número de cladódio por ordem/planta da palma forrageira cv. Gigante, aos nove meses de idade, cultivada sob telado

Table 1 - Total number of cladodes/plant and number of cladodes by order/plant of cactus forage cv. Gigante, at 9 monhts of growth, cultivated in a green house

Tratamentos

Treatments
Número total de cladódio/planta ${ }^{1}$ Total number of cladodes/plant
Número de cladódio por ordem/planta Number of cladodes by order/plant

\begin{tabular}{cc}
\hline Primário $^{2}$ & $\begin{array}{c}\text { Secundário }^{1} \\
\text { Primary }^{\text {Secondary }}\end{array}$ \\
1,25 & $0,75^{\mathrm{b}}$ \\
1,00 & $0,00^{\mathrm{b}}$ \\
1,75 & $0,75^{\mathrm{b}}$ \\
1,50 & 0,25 \\
1,25 & $0,25^{\mathrm{b}}$ \\
1,50 & $0,50^{\mathrm{b}}$ \\
1,50 & $0,25^{\mathrm{b}}$ \\
1,25 & $0,25^{\mathrm{b}}$ \\
2,00 & $1,33^{\mathrm{a}}$ \\
1,75 & $0,75^{\mathrm{a}}$ \\
1,75 & $0,50^{\mathrm{b}}$ \\
2,00 & $0,75^{\mathrm{b}}$ \\
1,25 & $2,00^{\mathrm{a}}$ \\
1,50 & $1,25^{\mathrm{a}}$ \\
2,00 & $1,00^{\mathrm{a}}$ \\
1,25 & 1,75 \\
2,00 & $2,00^{\mathrm{a}}$ \\
1,56 & 0,84 \\
12,92 & 19,59 \\
\hline
\end{tabular}

${ }^{1}$ Médias seguidas por igual letra, no sentido da coluna, não diferem $(P>0,05)$ pelo teste de Scott-Knott.

2 Não-significativa $(P>.05)$ pelo teste $F$.

3 Solução de macronutrientes completa (SMC).

${ }_{1}^{1}$ Means followed by equal letters, at same the column, do not differ $(P>.05)$ by Scott-Knott test.

2 Not significant $(P>0.05)$ by $F$ test.

${ }^{3}$ Complete macronutrients solution (CMS).

$(\mathrm{P}<0,05)$, por outro lado a subtração de $\mathrm{Ca}, \mathrm{Mg}$ e $\mathrm{S}$, não surtiu o mesmo efeito.

Vale ressaltar que, no local onde foi retirada amostra do solo e constatado o amarelecimento da palma, a realização de adubação e calagem propiciou a recuperação do palmal, desaparecendo o sintoma de amarelecimento, indicando que a fertilidade do solo é um dos fatores que influenciou no amarelecimento das plantas.

Os resultados obtidos para comprimento, largura, perímetro e espessura dos cladódios, conforme os tratamentos experimentais, são apresentados na Tabela 2. A análise de variância revelou efeito não significativo $(\mathrm{P}>0,05)$ entre os tratamentos pelo teste $\mathrm{F}$ para todas as características avaliadas. A média geral dos tratamentos para comprimento e largura foi de 29,11 e 11,79 cm, respectivamente. Santos (1989) encontrou resultados superiores para comprimento e largura dos cladódios, sendo de 33,56 e $18,37 \mathrm{~cm}$, respectivamente, o que pode estar associado à idade da planta, pois os autores trabalharam com a palma aos quatro anos de idade e provavelmente deve ter sido mensurado um grande número de cladódios expandidos. Neste trabalho, grande parte dos cladódios mensurada era nova e em expansão.

O perímetro médio e espessura média dos cladódios foram de 64,55 e 1,13 cm, respectivamente. Resultados diferentes foram encontrados por Teles et al. (1999) para espessura da palma forrageira clone IPA-20, aos quatro meses de idade, sendo de $0,73 \mathrm{e} 1,45 \mathrm{~cm}$, com a palma adubada com $800 \mathrm{~kg}$ de $\mathrm{P}_{2} \mathrm{O}_{5}+0 \mathrm{~kg}$ de $\mathrm{K}_{2} \mathrm{O}$ e $800 \mathrm{~kg}$ de $\mathrm{P}_{2} \mathrm{O}_{5}+800 \mathrm{~kg}$ de $\mathrm{K}_{2} \mathrm{O}$, respectivamente. A amplitude de variação para o perímetro máximo e mínimo do presente trabalho foi de 69,42 e $58,23 \mathrm{~cm}$, respectivamente.

$\mathrm{Na}$ Tabela 3, são apresentados os resultados obtidos para área de cladódio (AC) e índice de área de cladódio (IAC), da palma forrageira cv. Gigante. A análise de variância evidenciou diferença significativa $(\mathrm{P}<0,05)$ entre tratamentos para as características avaliadas. Para área de cladódio/planta e índice 
Tabela 2 - Valores médios de comprimento, largura, perímetro e espessura das brotações da palma forrageira cv. Gigante, aos 9 meses de idade

Table 2 - Mean values of length, width, perimeter and thickness of cladodes from cactus forage cv. Gigante, at 9 months of growth

\begin{tabular}{|c|c|c|c|c|}
\hline $\begin{array}{l}\text { Tratamentos } \\
\text { Treatments }\end{array}$ & $\begin{array}{c}\text { Comprimento }^{1}(\mathrm{~cm}) \\
\text { Lenght }\end{array}$ & $\begin{array}{c}\text { Largura }^{1}(\mathrm{~cm}) \\
\text { Width }\end{array}$ & $\begin{array}{c}\text { Perímetro }^{1}(\mathrm{~cm}) \\
\text { Perimeter }\end{array}$ & $\begin{array}{c}\text { Espessura }^{1}(\mathrm{~cm}) \\
\text { Thickness }\end{array}$ \\
\hline Testemunha & 26,56 & 11,03 & 58,94 & 1,10 \\
\hline Testemunha + nematicida & 31,83 & 12,67 & 69,33 & 1,30 \\
\hline Testemunha $+\mathrm{N}$ & 26,19 & 10,67 & 58,23 & 1,09 \\
\hline Testemunha $+\mathrm{P}$ & 29,63 & 11,38 & 64,81 & 1,19 \\
\hline Testemunha $+\mathrm{K}$ & 31,25 & 12,25 & 69,38 & 1,10 \\
\hline Testemunha $+\mathrm{Ca}$ & 27,98 & 11,21 & 61,96 & 1,03 \\
\hline Testemunha $+\mathrm{Mg}$ & 30,19 & 11,44 & 66,21 & 1,08 \\
\hline Testemunha $+\mathrm{S}$ & 28,81 & 12,50 & 64,81 & 0,99 \\
\hline $\mathrm{SMC}^{2}$ & 28,52 & 12,23 & 64,08 & 1,18 \\
\hline $\mathrm{SMC}-\mathrm{N}$ & 30,03 & 12,09 & 66,01 & 1,09 \\
\hline SMC - P & 31,60 & 12,85 & 69,42 & 1,09 \\
\hline SMC - K & 29,17 & 10,65 & 64,76 & 1,16 \\
\hline $\mathrm{SMC}-\mathrm{Ca}$ & 27,93 & 11,39 & 62,47 & 1,09 \\
\hline $\mathrm{SMC}-\mathrm{Mg}$ & 29,56 & 12,87 & 66,23 & 1,17 \\
\hline SMC - S & 29,58 & 12,47 & 66,57 & 1,12 \\
\hline SMC + Micro & 28,35 & 11,57 & 63,07 & 1,23 \\
\hline SMC + Micro + nematicida & 27,62 & 11,19 & 61,06 & 1,20 \\
\hline Médias (Means) & 29,11 & 11,79 & 64,55 & 1,13 \\
\hline $\mathrm{CV}(\%)$ & 13,41 & 13,32 & 12,38 & 13,04 \\
\hline
\end{tabular}

${ }_{1}^{1}$ Não-significativo pelo teste $\mathrm{F}(\mathrm{P}>0,05)$ (Complete macronutrients solution ([CMS]).

2 Solução de macronutrientes completa (SMC) (Not significant $[P>.05]$ by $F$ test).

de área de cladódio os tratamentos SMC, SMC com subtração dos nutrientes, SMC + micronutrientes e $\mathrm{SMC}+$ micronutrientes + nematicida, diferiram estatisticamente dos tratamentos testemunha, testemunha mais adição dos nutrientes e testemunha mais nematicida.

A adição de micronutrientes e nematicida não apresentou efeito significativo $(\mathrm{P}>0,05)$ para área de cladódio e índice de área de cladódio.

A média geral do índice de área de cladódio (IAC) da palma forrageira dos tratamentos foi de 1,15. Este valor pode ser considerado baixo, quando comparado a outras forrageiras, principalmente gramíneas, o que pode estar associado ao maior número de folhas, enquanto que a palma apresenta menor número de brotações/planta, sendo em média 2,42. Santos (1992) encontrou 0,164 para o IAC da palma Gigante aos nove meses de idade, sendo este valor ainda bem inferior ao encontrado neste trabalho, que foi em decorrência do tipo de espaçamento utilizado, onde o autor utilizou o espaçamento $2,0 \mathrm{~m} \times 1,0 \mathrm{~m}$. Apesar de a área considerada neste trabalho ter sido a do vaso, mesmo considerando o espaçamento $1,0 \mathrm{~m} \times 0,25 \mathrm{~m}$, o IAC da palma seria de 0,32 .

Para produção de matéria seca da parte aérea da
Tabela 3 - Área de cladódio/planta e índice de área de cladódio, da palma forrageira cv. Gigante aos 9 meses de idade

Table 3 - Cladode area/plant and cladode area index, of forage cactus cv. Gigante, at 9 months of growth

\begin{tabular}{lcc}
$\begin{array}{l}\text { Tratamentos } \\
\text { Treatments }\end{array}$ & $\begin{array}{c}\text { Área de cladódio } \\
\text { /planta }\left(\mathrm{cm}^{2}\right) \\
\text { Cladode area } \\
\text { plant }\end{array}$ & $\begin{array}{c}\text { Índice de área } \\
\text { de cladódio } \\
\text { Cladode area } \\
\text { index }\end{array}$ \\
\hline Testemunha & $571,27^{\mathrm{b}}$ & $0,81^{\mathrm{b}}$ \\
Testemunha + nematicida & $403,12^{\mathrm{b}}$ & $0,57^{\mathrm{b}}$ \\
Testemunha + N & $753,27^{\mathrm{b}}$ & $1,07^{\mathrm{b}}$ \\
Testemunha + P & $618,29^{\mathrm{b}}$ & $0,88^{\mathrm{b}}$ \\
Testemunha + K & $582,52^{\mathrm{b}}$ & $0,80^{\mathrm{b}}$ \\
Testemunha + Ca & $625,77^{\mathrm{b}}$ & $0,89^{\mathrm{b}}$ \\
Testemunha +Mg & $576,16^{\mathrm{b}}$ & $0,82^{\mathrm{b}}$ \\
Testemunha + S & $523,79^{\mathrm{b}}$ & $0,74^{\mathrm{b}}$ \\
SMC & $1146,25^{\mathrm{a}}$ & $1,62^{\mathrm{a}}$ \\
SMC - N & $835,27^{\mathrm{a}}$ & $1,18^{\mathrm{a}}$ \\
SMC - P & $908,09^{\mathrm{a}}$ & $1,29^{\mathrm{a}}$ \\
SMC - K & $947,49^{\mathrm{a}}$ & $1,34^{\mathrm{a}}$ \\
SMC - Ca & $1069,99^{\mathrm{a}}$ & $1,52^{\mathrm{a}}$ \\
SMC - Mg & $1018,42^{\mathrm{a}}$ & $1,44^{\mathrm{a}}$ \\
SMC - S & $1104,05^{\mathrm{a}}$ & $1,56^{\mathrm{a}}$ \\
SMC + Micro & $911,24^{\mathrm{a}}$ & $1,29^{\mathrm{a}}$ \\
SMC+Micro+nematicida & $1193,88^{\mathrm{a}}$ & $1,69^{\mathrm{a}}$ \\
Médias (Means) & 811,11 & 1,15 \\
CV (\%) & 24,26 & 22,98 \\
\hline
\end{tabular}

Médias seguidas por igual letra, no sentido da coluna, não diferem $(P>0,05)$ pelo teste de Scott-Knott.

1 Solução de macronutrientes completa (SMC).

Means followed by equal letters, at same the column, do not differ $(P>$. 05) by Scott-Knott.

${ }^{1}$ Complete macronutrients solution (CMS). 
planta, a análise de variância evidenciou diferença significativa $(\mathrm{P}<0,05)$ entre os tratamentos (Tabela 4). Os tratamentos SMC, SMC com subtração de nutrientes, $\mathrm{SMC}+$ micronutrientes e $\mathrm{SMC}+$ micronutrientes + nematicida foram superiores aos demais tratamentos, variando de $24,44 \mathrm{~g}$ de MS/vaso a 61,63 g de MS/vaso. Os tratamentos SMC e SMC + micronutrientes + nematicida apresentaram os maiores valores de produção de matéria seca. Tais resultados podem estar associados ao maior número de brotações novas. A testemunha apresentou produção de matéria seca de 30,62 g/vaso. Pessoa et al. (1999), estudando os efeitos da adubação mineral na palma forrageira clone IPA-20, com seis meses de idade em casa de vegetação, obtiveram para produção de matéria seca 91,25 g/vaso, no nível equivalente a $200 \mathrm{~kg} / \mathrm{ha}$ de $\mathrm{P}_{2} \mathrm{O}_{5}$. Já no nível equivalente a $0 \mathrm{~kg} / \mathrm{ha}$ de $\mathrm{P}_{2} \mathrm{O}_{5}$ foi obtido o valor de 79,69 g/vaso.

Estes resultados foram superiores aos encontrados neste trabalho, o que pode ser explicado pelo fato de se tratar da palma com sintoma de amarelecimento, como também a cultivar utilizada, em que Santos (1992) destacou o clone IPA-20 como mais produtivo, com superioridade em torno de 50\%, quando comparado com a palma Gigante, o cultivar utilizado no presente trabalho.

Observa-se que o grupo dos tratamentos SMC apresentou maior produção de matéria seca (Tabela 4), em relação ao grupo das testemunhas, evidenciando o efeito da fertilidade do solo na produção de matéria seca da palma forrageira.

Pela análise de variância não se observou significância $(\mathrm{P}>0,05)$ do teste $\mathrm{F}$ para os teores de matéria seca da planta (Tabela 4). A média de matéria seca observada foi de $72,90 \mathrm{~g}$. $\mathrm{kg}^{-1}$, tendo como limites mínimo e máximo os valores de 60,00 e 88,80 g. $\mathrm{kg}^{-1}$, respectivamente. Estes valores são considerados baixos, quando comparados com os encontrados por Santos et al. (1997), que obtiveram $102,00 \mathrm{~g} \cdot \mathrm{kg}^{-1}$. Os baixos valores nos teores de matéria

Tabela 4 - Produção de matéria seca (PMS) e teor de matéria seca (MS) da planta e da raiz da palma forrageira cv. Gigante aos 9 meses de idade

Table 4 - Dry matter yield (DMY) and dry matter content (DM) of aerial portion and roots of cactus forage cv. Gigante at 9 months of growth

\begin{tabular}{|c|c|c|c|c|}
\hline \multirow[b]{2}{*}{$\begin{array}{l}\text { Tratamentos } \\
\text { Treatments }\end{array}$} & \multicolumn{2}{|c|}{$\begin{array}{c}\text { Planta } \\
\text { Plant }\end{array}$} & \multicolumn{2}{|c|}{$\begin{array}{l}\text { Raiz } \\
\text { Root }\end{array}$} \\
\hline & $\begin{array}{c}\text { PMS } \\
\text { (g/vaso) } \\
D M Y \\
\text { (g/pot) }\end{array}$ & $\begin{array}{c}\mathrm{MS}^{1} \\
\left(\mathrm{~g} \cdot \mathrm{kg}^{-1}\right) \\
D M^{1} \\
\left(g \cdot \mathrm{kg}^{-1}\right)\end{array}$ & $\begin{array}{c}\text { PMS } \\
\text { (g/vaso) } \\
D M P \\
\text { (g/pot) }\end{array}$ & $\begin{array}{c}\mathrm{MS}^{1} \\
\left(\mathrm{~g} \cdot \mathrm{kg}^{-1}\right) \\
D M^{1} \\
\left(\mathrm{~g} \cdot \mathrm{kg}^{-1}\right)\end{array}$ \\
\hline Testemunha & $30,62^{b}$ & 76,50 & 16,42 & 182,10 \\
\hline Testemunha + nematicida & $24,44^{\mathrm{b}}$ & 64,80 & 17,13 & 157,60 \\
\hline Testemunha $+\mathrm{N}$ & $35,78^{b}$ & 87,70 & 30,65 & 155,60 \\
\hline Testemunha $+\mathrm{P}$ & $31,49^{\mathrm{b}}$ & 71,20 & 23,84 & 162,20 \\
\hline Testemunha $+\mathrm{K}$ & $33,58^{b}$ & 77,40 & 22,48 & 151,50 \\
\hline Testemunha $+\mathrm{Ca}$ & $34,73^{b}$ & 88,80 & 18,43 & 151,30 \\
\hline Testemunha $+\mathrm{Mg}$ & $33,10^{\mathrm{b}}$ & 79,90 & 22,90 & 149,40 \\
\hline Testemunha $+\mathrm{S}$ & $27,29^{b}$ & 82,30 & 19,41 & 167,20 \\
\hline $\mathrm{SMC}^{2}$ & $61,63^{\mathrm{a}}$ & 67,90 & 29,89 & 160,20 \\
\hline $\mathrm{SMC}-\mathrm{N}$ & $43,08^{\mathrm{a}}$ & 71,90 & 26,08 & 148,10 \\
\hline $\mathrm{SMC}-\mathrm{P}$ & $56,97^{\mathrm{a}}$ & 82,70 & 32,69 & 177,10 \\
\hline $\mathrm{SMC}-\mathrm{K}$ & $51,57^{\mathrm{a}}$ & 70,60 & 39,42 & 147,40 \\
\hline $\mathrm{SMC}-\mathrm{Ca}$ & $46,16^{\mathrm{a}}$ & 60,00 & 25,41 & 127,90 \\
\hline $\mathrm{SMC}-\mathrm{Mg}$ & $50,40^{\mathrm{a}}$ & 61,50 & 31,09 & 152,30 \\
\hline $\mathrm{SMC}-\mathrm{S}$ & $57,06^{\mathrm{a}}$ & 69,50 & 29,03 & 133,60 \\
\hline SMC + Micro & $49,94^{\mathrm{a}}$ & 66,40 & 27,14 & 141,00 \\
\hline $\mathrm{SMC}+\mathrm{Micro}+$ nematicida & $58,52^{\mathrm{a}}$ & 61,00 & 28,67 & 150,80 \\
\hline Médias (Means) & 42,73 & 72,90 & 25,92 & 153,90 \\
\hline $\mathrm{CV}(\%)$ & 20,83 & 19,03 & 36,40 & 18,34 \\
\hline
\end{tabular}

Médias seguidas por igual letra, no sentido da coluna, não diferem $(P>0,05)$ pelo teste de Scott-Knott.

1 Não-significativo $(P>0,05)$ pelo teste $F$.

2 Solução de macronutriente completa (SMC).

Means followed by equal letters, at same the column, do not differ $(P>.05)$ by Scott-Knott

${ }^{1}$ Not significant $(P>.05)$ by $F$ test.

${ }^{2}$ Complete macronutrients solution (CMS).

R. Bras. Zootec., v.31, n.1, p.52-60, 2002 
seca da palma podem estar associados ao crescimento lento apresentado pelas plantas CAM (Larcher, 1986), quando comparadas as plantas $\mathrm{C} 3 \mathrm{e} \mathrm{C} 4$, mantendo seu valor nutritivo por mais tempo, como também pelo fato de se tratar de um experimento onde foram realizadas irrigações freqüentes, o que contribui para uma maior umidade dos cladódios da planta.

Vale ressaltar que os menores valores nos teores de matéria seca observados, em relação à literatura, também podem estar relacionados à idade da planta avaliada neste trabalho, que foi de nove meses, e a presença de cladódios novos e, provavelmente, em expansão.

Para produção de matéria seca e teor de matéria seca da raiz, a análise de variância não evidenciou diferença significativa $(\mathrm{P}>0,05)$ entre os tratamentos pelo teste $\mathrm{F}$.

O elevado coeficiente de variação observado para produção de matéria seca das raízes está relacionado à grande dificuldade de se trabalhar com este componente da planta. No momento da colheita das raízes, ocorreram perdas durante a separação das mesmas do solo, apesar desse procedimento ter sido realizado com muito cuidado.

Para todas as características avaliadas do cladódio-planta, a análise de variância indicou efeito não significativo $(\mathrm{P}>0,05)$ entre os tratamentos pelo teste F (Tabela 5).

Vale ressaltar que o peso médio de matéria verde obtido no final do experimento $(1.009,33 \mathrm{~g} / \mathrm{vaso})$ foi menor que o peso desses mesmos cladódios no momento do plantio (1.123,37 g/vaso), o que pode estar associado à ocorrência de danos causados por fungos e pelo amarelecimento. Os teores de matéria seca dos cladódios-planta variaram de 58,00 a 87,70 g. $\mathrm{kg}^{-1}$. Estes valores são considerados baixos quando comparados aos resultados encontrados por Santos et al. (1997), de 102,00 g. $\mathrm{kg}^{-1}$, podendo estar relacionado à idade da planta, bem como ao sistema de irrigação utilizado neste trabalho.

Os dados médios de percentagem da biomassa seca da parte aérea e raiz da palma forrageira cv. Gigante são apresentados na Tabela 6. A análise de variância não evidenciou diferença significativa $(\mathrm{P}>0,05)$ entre os tratamentos pelo teste $\mathrm{F}$ para todas as características avaliadas. As médias gerais para biomassa seca da parte aérea e raiz foram 80,82 e $19,19 \%$, respectivamente, evidenciando que a palma forrageira, independentemente do tratamento, mobiliza grande parte dos nutrientes para aumentar a parte aérea.
Tabela 5 - Peso de matéria seca e teor de matéria seca (MS) do cladódio-planta da palma forrageira cv. Gigante, aos 9 meses de idade

Table 5 - Dry matter weight and dry matter content (DM) of cladodes-plant of cactus forage cv. Gigante, at 9 months of growth

\begin{tabular}{lcc}
\hline $\begin{array}{l}\text { Tratamentos } \\
\text { Treatments }\end{array}$ & $\begin{array}{c}\text { Peso de matéria seca } \\
(\mathrm{g} / \text { vaso }) \\
\text { Dry matter weight } \\
(\mathrm{g} / \text { pot })\end{array}$ & $\begin{array}{c}\mathrm{MS}^{1} \\
\left(\mathrm{~g} . \mathrm{kg}^{-1}\right) \\
\left(\mathrm{DM}^{1}\right) \\
\left(\mathrm{g} \cdot \mathrm{kg}^{-1}\right)\end{array}$ \\
\hline Testemunha & 59,34 & 87,70 \\
Testemunha + nematicida & 68,71 & 60,60 \\
Testemunha + N & 55,52 & 63,50 \\
Testemunha + & 66,65 & 64,90 \\
Testemunha + K & 68,07 & 65,20 \\
Testemunha + Ca & 65,41 & 66,20 \\
Testemunha +Mg & 59,89 & 58,00 \\
Testemunha + S & 60,81 & 72,10 \\
SMC & 67,03 & 62,00 \\
SMC - N & 72,22 & 64,00 \\
SMC - P & 69,86 & 64,90 \\
SMC - K & 74,48 & 76,00 \\
SMC-Ca & 61,08 & 87,50 \\
SMC - Mg & 64,41 & 61,90 \\
SMC - S & 61,30 & 64,20 \\
SMC+ Micro & 69,41 & 60,40 \\
SMC+ Micro + nematicida & 65,88 & 60,90 \\
Médias (Means) & 65,30 & 67,10 \\
CV (\%) & 12,98 & 20,68 \\
\hline
\end{tabular}

${ }^{1}$ Não-significativa $(P>0,05)$ pelo teste $F$.

2 Solução de macronutriente completa (SMC).

${ }^{1}$ Not significant $(P>.05)$ by $F$ test.

2 Complete macronutrients solution(CMS).

Com relação a nematóide, na Tabela 7 são apresentados os resultados obtidos da quantidade de espécimes por gêneros de nematóides encontrados no solo e na raiz da palma forrageira cv. Gigante. Vale ressaltar que o uso de nematicida como tratamento experimental e a investigação de tipos de nematóides ocorrentes na palma forrageira, deveu-se a avaliações preliminares na área onde ocorreu o sintoma de amarelecimento, em que foi constatada a presença de nematóides.

Níveis acima de 50 espécimes por $300 \mathrm{~cm}^{3}$ de solo podem ser prejudiciais às culturas, no entanto, não existe na literatura níveis de danos de nematóides para a palma forrageira (Moura, 2000). Barker \& Nusbaum, citados por Maaze (1979), afirmaram que o limite de intensidade de ataque de $M$. incognita no tomateiro corresponde a 25 a 50 nematóides por $500 \mathrm{~cm}^{3}$ de solo.

Observa-se que para todos os tratamentos a quantidade de espécimes de nematóides encontrada no solo foi superior ao do nível crítico das culturas, 
Tabela 6 - Porcentagens de biomassa seca da parte aérea e raiz da palma forrageira cv. Gigante, aos 9 meses de idade

Table 6 - Dry biomass of aerial portion and roots of cactus forage cv. Gigante, at 9 months of growth

\begin{tabular}{lcc}
\hline $\begin{array}{l}\text { Tratamentos } \\
\text { Treatments }\end{array}$ & $\begin{array}{c}\text { Alocação de biomassa seca }(\%) \\
\text { Dry biomass allocation }\end{array}$ \\
\cline { 2 - 3 } & $\begin{array}{c}\text { Parte aérea } \\
\text { Aerialportion }\end{array}$ & $\begin{array}{c}\text { Raiz } \\
\text { Root }\end{array}$ \\
\hline Testemunha & 84,52 & 15,48 \\
Testemunha + nematicida & 84,75 & 15,27 \\
Testemunha + N & 75,92 & 24,08 \\
Testemunha + P & 80,78 & 19,22 \\
Testemunha + K & 82,56 & 17,64 \\
Testemunha + Ca & 85,09 & 14,91 \\
Testemunha +Mg & 80,01 & 19,99 \\
Testemunha + S & 82,34 & 17,66 \\
SMC & 77,37 & 22,63 \\
SMC - N & 81,61 & 18,39 \\
SMC - P & 80,54 & 19,46 \\
SMC - K & 78,07 & 21,93 \\
SMC - Ca & 79,69 & 20,31 \\
SMC - Mg & 78,55 & 21,45 \\
SMC - S & 80,07 & 19,93 \\
SMC + Micro & 81,21 & 18,79 \\
SMC + Micro + nematicida & 80,93 & 19,07 \\
Médias (Means) & 80,82 & 19,19 \\
CV (\%) & 5,90 & 24,95 \\
\hline INo-sifat & &
\end{tabular}

${ }^{1}$ Não-significativa $(P>0,05)$ pelo teste $F$.

2 Solução de macronutriente completa (SMC).

${ }^{1}$ Not significant $(P>05)$ by $F$ test.

${ }^{2}$ Complete macronutrients solution (CMS). exceto nos tratamentos SMC - Mg e testemunha + nematicida, sendo que nestes as quantidades de espécimes encontradas foram de 28 e 0 , respectivamente, possivelmente em função do poder de atuação do nematicida para este último tratamento.

Já na raiz, a quantidade de espécimes de nematóides encontrada em todos os tratamentos, exceto o tratamento testemunha, foram superiores ao do nível crítico, podendo no entanto, ser prejudicial para o cultivo da palma.

Apesar de a análise de nematóides não ter sido realizada com repetição, verificou-se tendência de o tratamento de nematicida associado a SMC + micronutrientes promover melhores resultados para número de cladódio/planta, número de cladódio/ordem, área de cladódio, índice de área de cladódio, produção de matéria seca, matéria seca do cladódio planta e raiz, produção de matéria seca da raiz e menor nota de dano quando da colheita.

Vale ressaltar que este trabalho não é conclusivo quanto a questão do amarelecimento da palma, ficando evidenciado, por observações in loco, o efeito da adubação na diminuição da sintomatologia do amarelecimento. Em futuros trabalhos deve-se, simultaneamente, testar o efeito dos tratamentos na

Tabela 7 - Quantidade de espécimes de nematóides dos gêneros Pratylenchus (P), Crinonemella (C), Trichodorus (T), Helicotylenchus $(\mathrm{H})$ e Meloidogyne $(\mathrm{M})$ encontrados no solo e raiz da palma cv. Gigante

Table 7 - Quantity of specimen by nematode genders Pratylenchus (P), Crinonemella (C), Trichodorus (T) Helicotylenchus (H) and Meloidogyne (M) found in soil and root of cactus forage cv. Gigante

\begin{tabular}{|c|c|c|c|c|c|c|c|}
\hline \multirow[t]{3}{*}{$\begin{array}{l}\text { Tratamentos } \\
\text { Treatments }\end{array}$} & \multicolumn{6}{|c|}{$\begin{array}{l}\text { Nematóides } \\
\text { Nematodes }\end{array}$} & \multirow{3}{*}{$\begin{array}{c}\text { Raiz }(10 \mathrm{~g}) \\
\text { Root }(10 \mathrm{~g}) \\
\mathrm{P}\end{array}$} \\
\hline & \multicolumn{6}{|c|}{$\begin{array}{c}\text { Solo }\left(300 \mathrm{~cm}^{3}\right) \\
\text { Soil }\left(300 \mathrm{~cm}^{3}\right)\end{array}$} & \\
\hline & $\mathrm{P}$ & $\mathrm{C}$ & $\mathrm{T}$ & $\mathrm{H}$ & $\mathrm{M}$ & $\begin{array}{l}\text { Total } \\
\text { Total }\end{array}$ & \\
\hline Testemunha & 0 & 140 & 28 & 0 & 0 & 168 & 0 \\
\hline Testemunha + nematicida & 0 & 0 & 0 & 0 & 0 & 0 & 84 \\
\hline Testemunha $+\mathrm{P}$ & 0 & 84 & 28 & 0 & 0 & 112 & 84 \\
\hline Testemunha $+\mathrm{K}$ & 28 & 28 & 0 & 0 & 28 & 84 & 196 \\
\hline Testemunha $+\mathrm{Ca}$ & 112 & 168 & 84 & 28 & 0 & 392 & 84 \\
\hline Testemunha+Mg & 28 & 168 & 140 & 0 & 28 & 364 & 84 \\
\hline Testemunha $+\mathrm{S}$ & 56 & 168 & 140 & 0 & 0 & 364 & 140 \\
\hline $\mathrm{SMC}^{1}$ & 84 & 56 & 56 & 0 & 0 & 196 & 644 \\
\hline SMC - N & 28 & 196 & 84 & 0 & 0 & 308 & 818 \\
\hline SMC - P & 28 & 84 & 0 & 28 & 84 & 224 & 756 \\
\hline SMC - K & 28 & 0 & 28 & 28 & 0 & 84 & 392 \\
\hline $\mathrm{SMC}-\mathrm{Ca}$ & 0 & 28 & 56 & 0 & 0 & 84 & 1064 \\
\hline $\mathrm{SMC}-\mathrm{Mg}$ & 0 & 28 & 0 & 0 & 0 & 28 & 812 \\
\hline SMC - S & 0 & 140 & 140 & 0 & 0 & 280 & 252 \\
\hline $\mathrm{SMC}+$ micro & 0 & 28 & 308 & 0 & 0 & 336 & 56 \\
\hline $\mathrm{SMC}+$ micro + nematicida & 28 & 28 & 196 & 0 & 0 & 252 & 112 \\
\hline
\end{tabular}

${ }^{1}$ Solução de macronutriente completa (SMC).

1 Complete macronutrients solution (CMS).

R. Bras. Zootec., v.31, n.1, p.52-60, 2002 
palma sem sintoma de amarelecimento, como também uma avaliação com repetição das raízes para verificar os efeitos dos tratamentos, em relação a nematóides.

O sintoma de amarelecimento apresentado nos cladódios-planta não foi observado no material que brotou a partir do cladódio-planta.

\section{Conclusões}

Não houve efeito dos micronutrientes e nematicida para número total de cladódio, número de cladódio secundário, área de cladódio, índice de área de cladódio e produção de matéria seca, no grupo dos tratamentos com solução de macronutrientes completa.

De maneira geral, a fertilização promoveu aumento crescente da palma forrageira cultivada em amostras de solo provenientes de Caruaru - PE.

A palma forrageira aloca cerca de $81 \%$ de sua biomassa seca na parte aérea e os $19 \%$ restantes nas raízes.

A aplicação do nematicida Furadan não influenciou o crescimento da palma forrageira, mas diminuiu o número de nematóides de todas as espécimes.

\section{Agradecimento}

Ao Prof. Romero Marinho, pela atenção recebida na identificação dos nematóides.

\section{Literatura Citada}

EMPRESA BRASILEIRA DE PESQUISA AGROPECUÁRIA EMBRAPA. Serviço Nacional de Levantamento e Conservação de Solos. Manual de métodos de análises de solo. Rio de Janeiro: Empresa Brasileira de Pesquisa Agropecuária, 1997. 212p.

HOAGLAND, D.R.; ARNON, D.I. The water - culture method for growing plants without soil. California: Agricultural Experiment Station, 1950. 347p.

JENKINS, W.R. A rapid centrifugal-flotation technique for separating nematodes from soil. Plant Disease Reporte, v.48, p.692-698, 1964.

LARCHER, W. 1986. Ecofisiologia vegetal. São Paulo: EPU, 1986. 319p.

LOBATO, E.; KOLNELIUS, E.; SANZONOWICZ, C. Adubação fosfatada em pastagens. In: PEIXOTO, A.M. (Ed.) Pastagens: fundamentos da exploração racional. Piracicaba: Fundação de Estudos Agrícolas "Luiz de Queiroz", 1994. p.155-188.
MAAZE, U.C. Interações entre Meloidogyne incognita (Kofoid e Write, 1919), Chitwood, 1949, e deficiências nutricionais em tomateiro (Lycopersicon esculentum Mill.). Recife: Universidade Federal Rural de Pernambuco, 1992. 102p. Dissertação (Mestrado em Solos) - Universidade Federal Rural de Pernambuco, 1992.

MOURA, R.M. Infestação de nematóides. Recife: Universidade Federal Rural de Pernambuco, 2000. (Comunicação pessoal).

PESSOA, R.A.S.; DUBEUX Jr., J.C., SANTOS, M.V.F. et al. Efeito da adubação mineral no crescimento da palma (Opuntia ficus indica Mill.) - clone IPA-20. In: CONGRESSO DE INICIAÇÃO CIENTÍFICA, 9., 1999, Recife. Anais... Recife: Universidade Federal Rural de Pernambuco, 1999. p.223.

SANTOS, D.C. Estimativa de parâmetros em caracteres de clones da palma forrageira (Opuntia ficus indica Mill $e$ Nopalea cochenillifera Salm-Dick). Recife: Universidade Federal Rural de Pernambuco, 1992. 119p. Dissertação (Mestrado em Botânica) - Universidade Federal Rural de Pernambuco, 1992.

SANTOS, D.C.; FARIAS, I.; LIRA, M.A.; TAVARES FILHO, J.J. et al. A palma forrageira (Opuntia ficus indica Mill e Nopalea cochenillifera Salm Dyck) em Pernambuco: cultivo e utilização. Recife: Empresa Pernambucana de Pesquisa Agropecuária. p.1-16.

SANTOS, M.V.F. Composição química, armazenamento e avaliação da palma forrageira (Opuntia ficus indica Mill. e Nopalea cochenillifera Salm-Dyck) na produção de leite, em Pernambuco. Recife: Universidade Federal Rural de Pernambuco, 1989. 120p. Dissertação (Mestrado em Nutrição Animal) - Universidade Federal Rural de Pernambuco, 1989.

SCOTT, A.J.; KNOTT, M. A cluster analysis method for grouping means in the analysis of variance. Biometrics, v.30, n.3, p.507-512, 1974.

SILVA, D.J. Análise de alimentos (Métodos químicos e biológicos). Viçosa, MG: Universidade Federal de Viçosa, 1990. 166p.

SILVA, M.C.; SANTOS, S.F.; SANTOS, M.V.F. et al. Características de crescimento de cultivares de palma forrageira (Opuntia e Nopalea). In: CONGRESSO DE INICIAÇÃO CIENTÍFICA, 8., 1998, Recife. Anais... Recife: Universidade Federal Rural de Pernambuco, 1998. p.251.

TELES, M.M.; DUBEUX Jr., J.C.B.; SANTOS, M.V.F. Efeito das adubações fosfatada e potássica no desenvolvimento da palma forrageira (Opuntia ficus indica Mill.) Clone IPA-20. In: SIMPÓSIO DE PESQUISA E PÓS-GRADUAÇÃO DA UFRPE, 2., 1999. Recife. Anais... Recife: Universidade Federal Rural de Pernambuco, 1999. p.124. 